\title{
Mineral magnetic characterization of archeological potsherds: an example from the Deccan Province, western Maharashtra, India
}

\author{
Jyotibala Singh $^{1}$, S. J. Sangode ${ }^{1, *}$ and P. D. Sabale ${ }^{2}$ \\ ${ }^{1}$ Department of Geology, Savitribai Phule Pune University, Pune 411 007, India \\ ${ }^{2}$ Deccan College Post-Graduate and Research Institute, Pune 411 006, India
}

The ancient (archaeological) and modern potsherds sourced from Deccan basaltic soils and sediments at selected sites in the Bhima and Godavari river basins of the western Maharashtra, India, show characteristic mineral magnetic properties. High magnetic susceptibilities $(\chi$ If $)$ for the Deccan-sourced sherds enable their distinction from other sources in the region. The modern pottery sourced from Deccan soils shows significant lower $\chi$ if than ancient pottery in the region, which further shows lower $\chi$ if than the associated soils (/sediments) due to successive removal of detrital grains as a function of improvement in the preprocessing techniques. The ancient and modern potteries show higher superparamagnetic content that is otherwise absent in the source, suggesting its neoformation during firing. High hematite content in modern pottery relative to ancient pottery further indicates higher oxidative firing in the former. Based on close examination of Isothermal Remanence Magnetization (IRM) acquisition rates, we suggest the ratios: IRM $_{1.8 \mathrm{mT}} / \mathrm{IRM}_{0.3-0.025} \mathrm{mT}$ and HIRM/Soft IRM $_{\text {along with }}$ other routine mineral magnetic parameters to estimate the relative degree of oxidative heating, source discrimination and the levels of pre-processing of raw material amongst the Deccan-sourced pottery. The present approach being rapid and economic, a large quantitative database can be generated from the potsherds for detailed characterization of these archaeological materials.

Keywords: Ancient pottery, basaltic soils and sediments, mineral magnetism, modern potsherds.

THE archaeological potsherds are some of the most extensively occurring artifacts to generate information on contemporary socio-economic and cultural habits ${ }^{1,2}$. The basic aspects of ceramic manufacturing techniques, firing conditions and provenance are usually described by classical methods in archaeology; and quantitative analytical approaches are $\mathrm{few}^{3-5}$. The source and pre-processing of raw material, and the firing practices are variable through different cultures $^{1-5}$ demanding analytical approaches to characterize the samples. Further, the

*For correspondence. (e-mail: sangode@rediffmail.com) discrimination of source is also useful to trace the trade pathways.

Iron oxides are the most common and distinctive compounds to readily undergo transformation during various levels of heating in the open air or different kiln conditions. Such changes are usually visible by colour, and can be identified as well as quantified using the well-established non-destructive approach of mineral magnetism ${ }^{6-8}$. The magnetic properties of different forms of iron oxides and hydroxides vary both as a function of composition, substitution and grain size, facilitating their potential usefulness in archaeology. The source material in the form of soils and sediments carries distinctive magnetic mineralogy, magnetic grain size or concentration of magnetic phases that are altered at higher temperatures. The physico-chemical, oxidative and reductive transformations during firing yield new iron compounds, and provide information on the firing temperatures and redox conditions. The routine mineral magnetic parameters are used to distinguish and quantify the iron-oxide compounds and their mixtures, and such attempts on artefacts elsewhere have been made to substantiate other experimental studies $^{9-13}$.

Pottery-making involves firing of the processed/ unprocessed earthen material at various temperatures under oxygen-poor or oxidative environments. Therefore, the source of the artifact as well as the temperature stages characteristic of the given ceramic material can be inferred by studying the iron-oxide transformations using mineral magnetism ${ }^{6,8,14-19}$. Here we explore the scope of mineral magnetism in characterization of the ceramic artefacts occurring over Deccan Province, Western Maharashtra, India.

\section{Study area and sampling}

The study area represents geologically and geomorphologically unique plateau marked by basaltic soils of the Deccan Volcanic Province (DVP) covering a large area of $>500,000 \mathrm{~km}^{2}$ (Figure 1). The Deccan trap lava flows develop thick tabular sheets of large aerial extent and flat-topped hills with step-like terraces and valleys. The Quaternary sediments in this region are represented by 


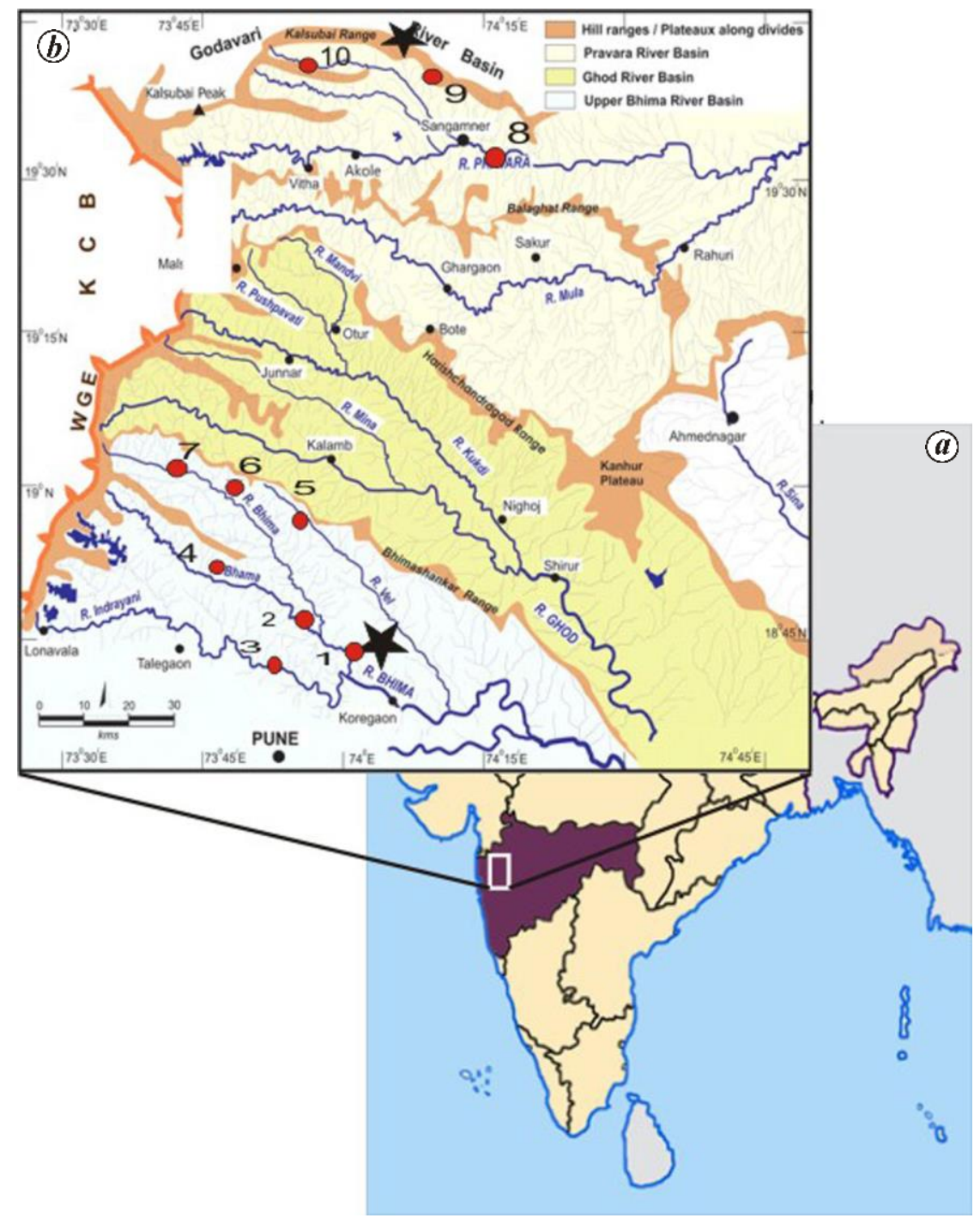

Figure 1. $\boldsymbol{a}$, Part of India showing the study area from western Maharashtra. $\boldsymbol{b}$, Location map of the study area (modified after Kale et al. $^{26}$ ).

older and newer alluvial deposits by existing rivers. The western part of the Province further represents laterites and lateritic soils. The sites from where the pottery samples were collected mainly fall in the Bhima River basin, with one site in Godavari basin within the DVP (Figure 1 and Table 1). Bhima is the major tributary of River Krishna, originating in the Sahyadri uplands in parts of Pune district, Maharashtra. It shows isolated patches of flood plains and partly eroded channel deposits, pediments and slack water deposits.

\section{Sampling strategy}

The stratigraphy of each locality was studied in detail from the available exposed section of cultural deposits apart from several new trenches ${ }^{20,21}$. At few places, habitation deposit was available in a very thin band, where cultural material was found on the surface. Table 1 provides details of sample collection for the present study. Figure 2 displays the representative site photographs. The potsherds were collected by the vertical method in stratigraphic layers in exposed section. Further, sherds of modern pottery were collected from potters in Pune (Kumbharwada, Keshav Nagar), denoting the samples as Modern-1 to Modern-10 for detailed magnetic analysis.

The potsherds from sites I-VII fall within Pune and Solapur districts of the Bhima basin while sites VIII-X belong to Aurangabad district of the Godavari basin (Table 1). Totally 15-20 sherds were collected, with each site representing 70-120 occurrences. Finally, three representative sherds were selected from each collection for detailed mineral magnetic analysis, denoting the samples as follows: site I - Bhigwan (B1 and B2), site II - Kondhar Chincholi (KC-1, KC-2, KC-3), site III - Katraj (KTJ-1, KTJ-2, KTJ-3), site IV - Kugaon (KGN-1, KGN-2, 
Table 1. Typological details of studied pottery collected from the Deccan Province, western Maharashtra, India

\begin{tabular}{|c|c|c|c|c|c|}
\hline Site/latitude-longitude/height & $\begin{array}{c}\text { Trench/ } \\
\text { strat. layer/ } \\
\text { depth }(\mathrm{cm}) / \\
\text { number of } \\
\text { potsherds } \\
\text { collected/ } \\
\text { refer Figure } 2\end{array}$ & Sample & Type & Colour & $\begin{array}{c}\text { Cultural } \\
\text { period }\end{array}$ \\
\hline Bhigwan & $\mathrm{A} 1 / 2 / 5.2 / 27$ & $\mathrm{~B} 1$ & Red slip & Red & Early historical \\
\hline $74^{\circ} 46^{\prime} 08^{\prime \prime} \mathrm{E}, 18^{\circ} 18^{\prime} 07^{\prime \prime} \mathrm{N} / 501 \mathrm{~m}$ & & B2 & Black slip & Black & Early historical \\
\hline Kondhar Chincholi & $\mathrm{A} 2 / 4 / 4 / 10$ & $\mathrm{KC} 1$ & Chocolate & Chocolate & Early historical \\
\hline \multirow[t]{2}{*}{$74^{\circ} 48^{\prime} 53^{\prime \prime} \mathrm{E}, 18^{\circ} 16^{\prime} 50^{\prime \prime} \mathrm{N} / 421.8 \mathrm{~m}$} & & $\mathrm{KC} 2$ & Red & Red & Early historical \\
\hline & & $\mathrm{KC} 3$ & Black & Black & Medieval \\
\hline Katraj & $\mathrm{A} 1 / 2 / 6.2 / 34$ & KTJ1 & Red slip & Chocolate & Early historical \\
\hline \multirow[t]{2}{*}{$74^{\circ} 22^{\prime} 24^{\prime \prime} \mathrm{E}, 18^{\circ} 17^{\prime} 15^{\prime \prime} \mathrm{N} / 452.93 \mathrm{~m}$} & & KTJ2 & Red ware & Red & Early historical \\
\hline & & KTJ3 & Black ware & Black & Early historical \\
\hline Kugaon & $\mathrm{A} 1 / 2 / 6.2 / 15$ & KGN1 & Red ware & Red & Early historical \\
\hline \multirow[t]{2}{*}{$75^{\circ} 06^{\prime} 14^{\prime \prime} \mathrm{E}, 18^{\circ} 12^{\prime} 87^{\prime \prime} \mathrm{N} / 496 \mathrm{~m}$} & & KGN2 & Grey ware & Grey & Medieval \\
\hline & & KGN3 & Black ware & Black & Medieval \\
\hline Sugaon & $\mathrm{B} 1 / 3 / 5.8 / 17$ & SGN1 & Red & Red & Early historical \\
\hline \multirow[t]{2}{*}{$75^{\circ} 02^{\prime} 51^{\prime \prime} \mathrm{E}, 18^{\circ} 16^{\prime} 69^{\prime \prime} \mathrm{N} / 498 \mathrm{~m}$} & & SGN2 & Red & Red & Early historical \\
\hline & & SGN3 & Black & Black & Medieval (?) \\
\hline Khed Bhalawani & $\mathrm{A} 1 / 4 / 5.2 / 12$ & $\mathrm{~KB} 1$ & Red slip & Red & Early historical \\
\hline \multirow[t]{2}{*}{$75^{\circ} 15^{\prime} 43^{\prime \prime} \mathrm{E}, 17^{\circ} 45^{\prime} 42^{\prime \prime} \mathrm{N} / 431 \mathrm{~m}$} & & KB2 & Red & Red & Early historical \\
\hline & & KB3 & Greyish-black & Grey & Early historical \\
\hline Machnur & $\mathrm{A} 2 / 1 / 5.8 / 32$ & MCNR1 & Red slip & Red & Early historical \\
\hline \multirow[t]{2}{*}{$75^{\circ} 33^{\prime} 58^{\prime \prime} \mathrm{E}, 17^{\circ} 33^{\prime} 87^{\prime \prime} \mathrm{N} / 1200 \mathrm{ft}$} & & MCNR2 & Red & Red & Early historical \\
\hline & & MCNR3 & Grey & Grey & Early historical \\
\hline Isarwadi & $\mathrm{B} 1 / 4 / 7.2 / 12$ & ISRWD1 & Outer - red/inner - black & Red/black & Early historical \\
\hline \multirow[t]{2}{*}{$75^{\circ} 21^{\prime} 138^{\prime \prime} \mathrm{E}, 19^{\circ} 34^{\prime} 243^{\prime \prime} \mathrm{N} / 460 \mathrm{~m}$} & & ISRWD2 & Red & Red & Early historical \\
\hline & & ISRWD3 & Black & Black & Early historical \\
\hline Dhanegaon & $\mathrm{A} 1 / 2 / 4.6 / 15$ & DHGN1 & Red slip & Red & Early historical \\
\hline \multirow[t]{2}{*}{$75^{\circ} 21^{\prime} 482^{\prime \prime} \mathrm{E}, 19^{\circ} 34^{\prime} 820^{\prime \prime} \mathrm{N} / 142.64 \mathrm{~m}$} & & DHGN2 & Red & Red & Early historical \\
\hline & & DHGN3 & Black & Black & Early historical \\
\hline Shivoor & $\mathrm{A} 2 / 2 / 4.4 / 25$ & SVR1 & Red ware & Red & Early historical \\
\hline \multirow[t]{2}{*}{$74^{\circ} 52^{\prime} 250^{\prime \prime} \mathrm{E}, 20^{\circ} 04^{\prime} 535^{\prime \prime} \mathrm{N} / 176.78 \mathrm{~m}$} & & SVR2 & Green ware & Green & Medieval \\
\hline & & SVR3 & Black slip & Deep black & Early historical \\
\hline
\end{tabular}

KGN-3), site V-Sugaon (SGN-1, SGN-2, SGN-3), site VI - Khed Bhalwani (KB-1, KB-2, KB-3), site VII Machnur (MCNR-1, MCNR-2, MCNR-3), site VIII Isarwadi (ISRWD-1, ISRWD-2, ISRWD-3), site IX Dhanegaon (DHGN-1, DHGN-2, DHGN-3) and site X - Shivoor (SVR-1, SVR-2, SVR-3).

\section{Materials and method}

\section{Mineral magnetic analysis}

For mineral magnetic analysis, each potsherd was washed thoroughly in distilled water, air-dried and further fragmented to fit maximum sample in the standard non-magnetic pots $(2.5 \mathrm{~cm}$ diameter and $2.2 \mathrm{~cm}$ height), and the weight of each filled pot was measured. The analysis was carried out in the Rock Magnetic Laboratory of the Department of Geology, Savitribai Phule Pune University. Magnetic susceptibility ( $\left.\chi_{\text {lf }}\right)$ is the most readily measurable parameter that in general estimates the bulk concentration of ferrimagnetic minerals ${ }^{6-8,22}$. The Deccan soils characteristically show high ferrimagnetic concentration due to their basaltic source. The susceptibilities of the potteries sourced from Deccan soils, therefore, have higher values than any other source in the surrounding region. Also, they provide better instrumental accuracies and discriminative values. When the samples are of unimodal ferrimagnetic nature, the susceptibilities are further influenced by the domain size equivalent to physical grain size, in addition to concentration. The low- and high-frequency magnetic susceptibilities ( $\chi_{\text {lf }}$ and $\chi_{\mathrm{hf}}$ ) were measured at 0.46 and $4.6 \mathrm{kHz}$ respectively, using the globally standard MS2B laboratory sensor of Bartington (UK). The frequency dependent susceptibility $\left(\chi_{\mathrm{fd}}\right)$ and its percentage $\left(\chi_{\mathrm{fd}} \%\right)$ were calculated for qualitative and quantitative estimates of finer supermagnetic (SP) fraction, or the fraction lying at the boundary of SP and single-domain (SD) grains. The SP fraction is often generated in soils as the pedogenic fraction, while it is also reported to be generated by open-air heating like wild fires $^{23}$. Anhysteretic remanence magnetization (ARM) was grown using an alternating field demagnetizer 


\section{RESEARCH ARTICLES}

(Magnon AFD-300, Germany) with peak alternating field of $100 \mathrm{mT}$ in the presence of DC bias field, and expressed as ARM susceptibility ${ }^{24}$. $\chi$ ARM represents the concentration of SD ferrimagnetic mineral ${ }^{25}$. Since the raw material for pottery is of clay to silt size, it anticipate abundance of SP, SD and pseudo-single domain (PSD) grains. The isothermal remanence magnetization (IRM) was induced in a stepwise manner in different forward fields up to $1000 \mathrm{mT}$ for all the samples, and up to $2200 \mathrm{mT}$ separately for selective samples showing high coercivities. The induced field was then demagnetized at various steps of back fields up to $-300 \mathrm{mT}$. The field was induced by an impulse magnetizer (ASC IM 10-30, USA) and remanance measured using a spinner magnetometer (Molspin, UK). The magnetization/demagnetization data produced from IRM analysis were used to estimate the concentration and granulometry-related parameters ${ }^{8}$. The saturation isothermal remanent magnetization (SIRM) was measured at $1000 \mathrm{mT}$, as majority of the samples are saturated well below $300 \mathrm{mT}$. SIRM is proportional to the ferrimagnetic concentration and provides complementary

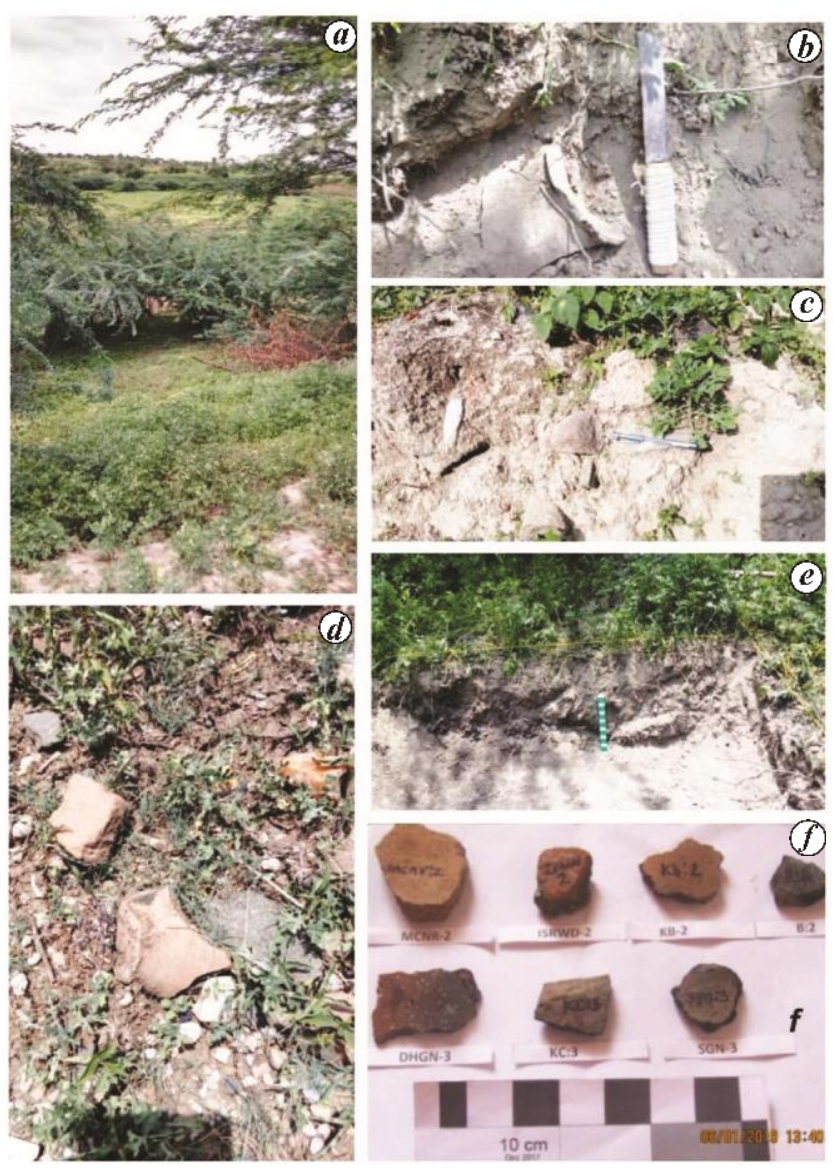

Figure 2. Representative photographs of sites for sample collection and some potsherds. $\boldsymbol{a}$, The surface and mounds at Bhigwan; $\boldsymbol{b}$, potsherds and associated soil at Katraj; $\boldsymbol{c}$, cultural deposits with pottery at Kugaon; $\boldsymbol{d}$, potsherds at Machnur; $\boldsymbol{e}$, layer of cultural deposit at Sugaon; $f$, some potsherds used in the present analysis. information to $\chi_{\text {If }}$ and $\chi_{\text {ARM. }}$. The soft isothermal remanent magnetization $\left[\right.$ Soft $_{\text {IRM }}=1 / 2\left(\right.$ SIRM - IRM $\left.\left._{-20 \mathrm{mT}}\right)\right]$ was calculated as a proxy to filter out the concentration of ferrimagnetic minerals. The hard isothermal remanent magnetization $\left[\mathrm{HIRM}=1 / 2\left(\mathrm{SIRM}+\mathrm{IRM}_{-300 \mathrm{mT}}\right)\right]$ estimates the concentration of antiferromagnetic minerals with bias to hematite in the present case. The SIRM/ $\chi_{\text {If }}$ ratio is diagnostic of either mineralogy or concentration, where the samples have similar mineral types. The demagnetization parameters $S$-ratios (IRM-100 mT/SIRM and IRM$300 \mathrm{mT} / \mathrm{SIRM})^{8}$ were calculated to identify the relative abundance of ferrimagnetic and antiferromagnetic minerals, and their domain sizes in bulk sample ${ }^{6}$. The coercivity of remanence $\left(B_{(\mathrm{O}) \mathrm{CR}}\right)$ is the reverse DC field acquired to reduce SIRM to zero, and is used for characterizing different magnetic minerals present in the sample. Temperature-dependent magnetic susceptibility $(k-T)$ was measured from room temperature up to $700^{\circ} \mathrm{C}$ for representative samples (using Bartington MS-2WFP apparatus) in order to estimate temperature-related transformations.

\section{Results and discussion}

The mean volume susceptibility for ancient potsherds is $119 \times 10^{-6}$ SI units, with median of 106 and maximum of 225 (Supplementary Table 1). This shows a large variability in the concentration of different pottery materials. Modern pottery shows a mean of 81 and maximum of $179 \times 10^{-6}$ SI units (Supplementary Table 2). The volume susceptibility for untreated Deccan trap soils (/sediments) falls in the range $300-500\left(\times 10^{-6}\right.$ SI units $)$. These high values in the modern sediment or soil are because of the abundance of ferrimagnetic detrital basalt grains. During the treatment of soils for pottery-making, majority of the detrital fragments are removed as coarse sand enriching the clay (paramagnetic) proportion, and in turn, decreasing the susceptibility.

The studied Deccan trap bedrock samples show very high values of $k_{\text {lf }}$ of the order of $800 \times 10^{-6}$ SI, with maximize value of $>1400$ (Supplementary Table 3 ). The $\chi_{\text {lf }}$ for ancient pottery is $38\left(\times 10^{-8} \mathrm{~m}^{3} / \mathrm{kg}\right)$, that for modern pottery is $25 \times 10^{-8} \mathrm{~m}^{3} / \mathrm{kg}$ and for the Deccan traps rock it is $125 \times 10^{-8} \mathrm{~m}^{3} / \mathrm{kg}$. This suggests efficient removal of sand/silt/clast fraction in modern pottery than that of ancient pottery due to better pre-processing of the former. We also analysed soils from the Gangetic plain used for pottery-making that show very low susceptibility $\left(<5 \times 10^{-8} \mathrm{~m}^{3} / \mathrm{kg}\right)$. This is due to the significantly low ferrimagnetic concentration of the Ganga alluvium compared to the Deccan soils. The mean frequency dependence of susceptibility for ancient potsherds is $2.63 \times 10^{-8} \mathrm{~m}^{3} / \mathrm{kg}$, with a maximum of 9.6 and average mean percentage of 7 . The frequency dependence for modern pottery is $1.19 \times 10^{-8} \mathrm{~m}^{3} / \mathrm{kg}$, with a maximum 
value of 2.2 and mean percentage of 7.46. The source for frequency dependence is the concentration of grains in the SP-ferrimagnetic range, or more particularly at the boundary of SP and SD.

The mean coercivity of remanance $\left(B_{(\mathrm{o}) \mathrm{CR}}\right)$ for ancient pottery is $51 \mathrm{mT}$, with a maximum value of $76 \mathrm{mT}$. The $B_{(\mathrm{o}) \mathrm{CR}}$ for modern pottery is 37 , with a maximum value of $70 \mathrm{mT}$. This suggests relative predominance of SDferrimagnet over antiferromagnets (hematite); and if hematite is present, it is likely to be fine-grained and amorphous in nature marked by low $B_{(\mathrm{o}) \mathrm{CR}}$. The ancient pottery shows very high $\chi_{\text {ARM }}$ compared to modern pottery. This further supports the fact that ancient pottery contains higher concentration of SD grains compared to modern pottery. IRM took higher fields of saturation for modern pottery compared to ancient pottery. This may be due to prolonged heating in more oxygenated environments (in air) for the modern pottery generating more ferric oxides (hematite), which is harder during IRM acquisition. The higher SD-ferrimagnetic content in ancient pottery may be due to a less oxygenated heating environment, or lower heating temperature. The mean $S$-ratio for ancient pottery is -0.5 , with a maximum of -0.76 and median of -0.53 depicting a range of SD-PSD and multi-domain ferrimagnetic grains. The $S$-ratio for modern pottery is -0.48 , with a range between 0.23 and -0.78 and a median of -0.58 , indicating a mixture of antiferromagnetic and ferrimagnetic oxides.

The Soft IRM $_{\text {for ancient pottery is } 21,170 \mathrm{Am}^{2} / \mathrm{kg}}$ compared to that of $2834 \mathrm{Am}^{2} / \mathrm{kg}$ for modern pottery. It suggests a characteristically high concentration of ferrimagnetic content for ancient pottery compared to modern pottery. This is again because of the better processing for modern pottery, removing majority of the coarse particles of the Deccan basalt weathered clasts. The SIRM/ $\chi$ if values for modern as well as ancient pottery are similar. Various sieves are commonly used by the modern potters to pre-process the material, removing the coarse- to medium-sized sand which is of detrital nature; is not likely the case for ancient potters. We can, therefore, infer that the mineral magnetic parameters indicating ferrimagnetic concentration ( $\chi_{\text {lf }}$, SIRM, SoftIRM) highlight the preprocessing efficiency. Thus, it shows the scope for parameterization of the level of processing amongst different pottery occurrences within the Deccan province.

The $\chi_{\text {If }}$ and $\chi_{\text {fd }}$ show a strong positive correlation (Supplementary Table 4), indicating that the susceptibility variation is controlled by SP-SD ferrimagnetic domain size. $\chi_{\mathrm{fd}}$ can therefore be a good parameter to indicate and characterize the pottery-making habits. $\chi_{\mathrm{fd}}$ is controlled by the source of clay used for pottery making. The positive correlation between $\chi_{\text {ARM }}$ and $\chi_{\text {lf }}\left(R^{2}=0.67\right)$ further supports the above condition. There is a strong negative correlation between $\mathrm{SIRM} / \chi_{\text {lf }}$ and $\chi_{\mathrm{fd}} \%\left(R^{2}=\right.$ $-0.87)$ as well as $B_{(\mathrm{o}) \mathrm{CR}}\left(R^{2}=-0.68\right)$. This indicates that $\chi_{\mathrm{fd}}$ decreases as a result of an increase in the harder frac- tion. The harder fraction, if it is ferrimagnetic, can be assigned to the SD grains, while for the antiferromagnetic fraction it can be hematite. Therefore, if there is any baking effect, it is consuming the ferrimagnetic $\chi_{\text {fd }}$, i.e. the finer SP ferromagnetic fraction; on the other hand, it can generate the finer antiferromagnetic oxides, i.e. SP antiferromagnetism. There is a positive correlation between $\mathrm{SIRM} / \chi_{\text {If }}$ and $B_{(\mathrm{o}) \mathrm{CR}}$, indicating their sensitivity to the harder fraction. Natural Remanance Magnetization (NRM) shows a strong positive correlation with ARM and also antiferromagnetic IRM (IRM-afm). The strong correlation of NRM with $\chi_{\text {ARM }}$ suggests its qualification to measure the palaeointensity for advanced palaeomagnetic studies. Its positive correlation with IRMafm further suggests that it is a function of heating. The RR index shows positive correlation with $\mathrm{NRM} / \chi_{\text {If }}$ and supports the idea that heating (baking) has greatly affected the NRM intensity of the pottery.

For modern pottery, there is a strong negative correlation between RR index and susceptibility (Supplementary Table 5). This indicates oxidation of majority of ferrimagnetic iron oxides into weakly magnetic antiferromagnetic oxide (hematite) during/after baking, thus decreasing the susceptibility. The significant positive correlation $\left(R^{2}=0.85\right)$ between $\chi_{\text {ARM }}$ and $\chi_{\text {lf }}$ suggest SDferrimagnetic control over susceptibility. Strong negative correlation of $\chi_{\mathrm{fd}} \%$ with $B_{(\mathrm{O}) \mathrm{CR}}, \mathrm{NRM}, \mathrm{ARM}$ and IRM, but positive correlation with RR index suggests that SP fraction is produced during heating. There is a strong positive correlation of NRM with $\chi_{\text {ARM }}$, depicting SDferrimagnetic grains to govern the NRM intensity.

Apart from pottery, the raw (unbaked) and partly processed soils of the Deccan Province and Ganga basin were analysed for rock magnetic study. The Deccan soils show high susceptibility compared to modern as well as ancient pottery, whereas the susceptibility for Ganga soils is very weak (almost 30 times lower). The coervicity and $S$-ratio for the Ganga alluvial soils are higher, indicating their antiferromagnetic nature. An archaeological brick from Aurangabad, Maharashtra shows very high susceptibility (even higher than the potsherds), while its coercivity matches with the potsherds and soils. This is because the raw material used for bricks is not processed to remove the coarse basaltic clast/fragments and detrital sands, resulting into higher ferrimagnetic concentration.

\section{Thermomagnetic analysis}

The thermomagnetic analysis shows titanomagnetite as the major constituents with various levels of Ti-substitution. The pre-baking processing aids in the removal of detrital ferrimagnets that are dominated by MD grains, thereby relatively enriching the SD ferrimagnets. The $\chi_{\mathrm{fd}}$ and $\chi$ ARM therefore being sensitive to SD domain size are significant to be parametrized to depict such changes. 

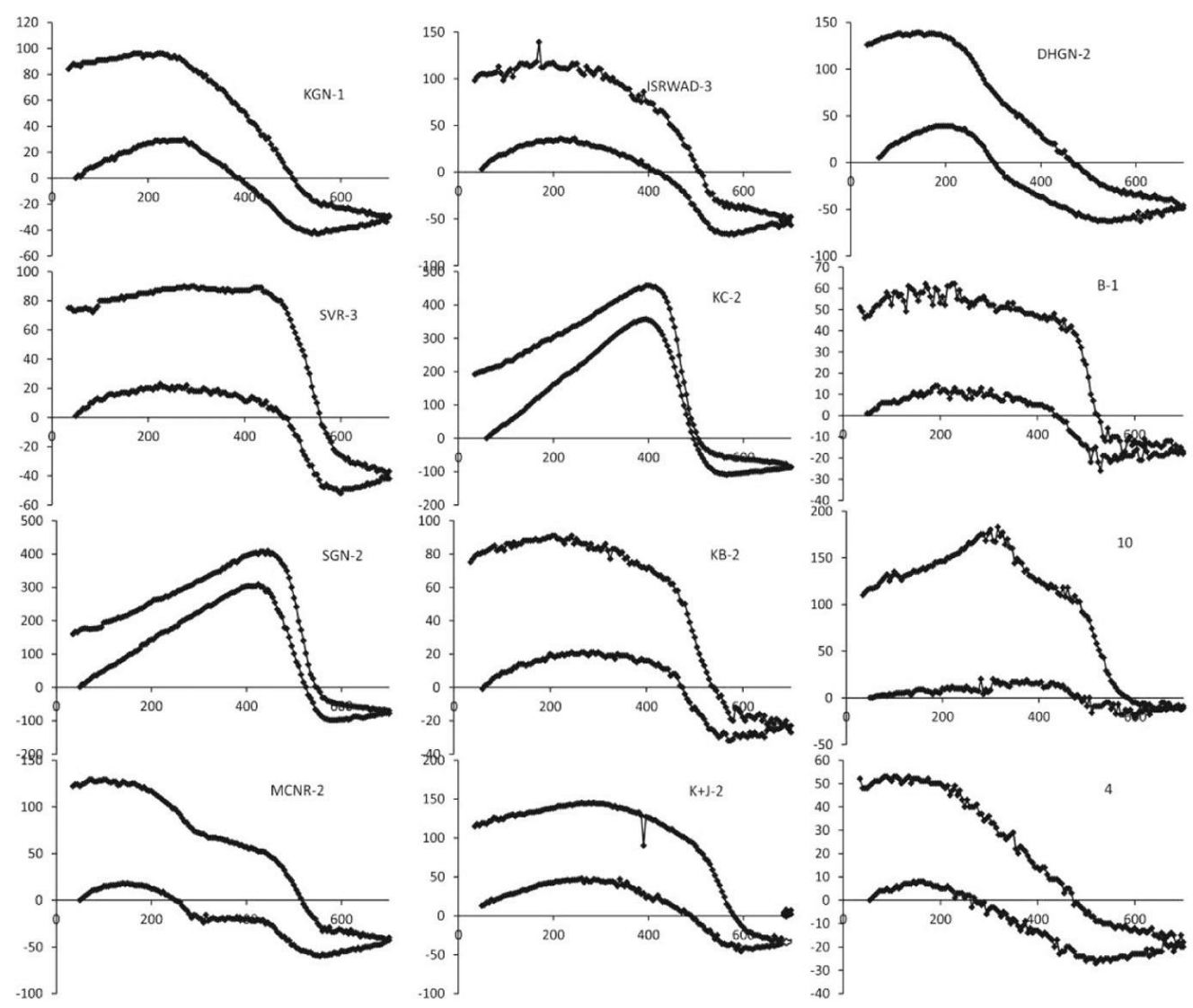

Figure 3. Susceptibility-temperature $(k-T)$ variation spectra for the ancient and modern pottery samples.

The heating appears to have increased the SP fraction, thereby relatively decreasing the SD fraction.

The susceptibility-temperature data have been documented in detail to note the initial volume susceptibility $\left(K_{\text {lf }}\right)$ at $50^{\circ} \mathrm{C}$, peak Klf, reverse gain, reverse peak and reverse $K_{\text {lf }}$ at $50^{\circ} \mathrm{C}$ for every sample (Supplementary Table 6) and the representative samples are described below.

The sample SVR-3 showed a peak of 90 at $295^{\circ} \mathrm{C}$ and a significant drop after $485^{\circ} \mathrm{C}$, suggesting Curie temperature $\left(T_{\mathrm{c}}\right)$ for titanomagnetite. The lowest value was reached at $555^{\circ} \mathrm{C}$, depicting $T_{\mathrm{c}}$ for titanomagnetite. Thereafter, Klf showed negative values and a maximum negative value of -52 was observed at $600^{\circ} \mathrm{C}$. Sample SVR-2 showed lower Klf of 24, with a peak of 39 occurring at $375^{\circ} \mathrm{C}$. The significant drop started at $500^{\circ} \mathrm{C}$ with a minimum occurring at $605^{\circ} \mathrm{C}$. SGN-2 showed a drop in $K$ lf beginning at a value of 68 at $530^{\circ} \mathrm{C}$, and the minimum Klf showed Curie temperature of $545^{\circ} \mathrm{C}$. Whereas the diamagnetic susceptibility of -98 occurred after $585^{\circ} \mathrm{C}$. The reverse gain started at $520^{\circ} \mathrm{C}$ and peak occurred at $405^{\circ} \mathrm{C}$. Finally, the susceptibility dropped to 1. This sample therefore showed a variety of titanomagnetites, i.e. mixing of the source.

MCNR-2 showed high Klf of 122 , with a peak of 129 at $105^{\circ} \mathrm{C}$. The drop started at $\mathrm{Klf}=98$ occurring at $245^{\circ} \mathrm{C}$ suggesting Ti-rich titanomagnetite. The diamagnetic peak of -60 occurred at $555^{\circ} \mathrm{C}$ on the reverse curve. The reverse gain started at $240^{\circ} \mathrm{C}$ with a peak at $275^{\circ} \mathrm{C}$ and fall to zero at $50^{\circ} \mathrm{C}$. $\mathrm{KGN}-1$ showed peak at $220^{\circ} \mathrm{C}$ with minimum $K$ lf occurring at $495^{\circ} \mathrm{C}$. It showed the diamagnetic peak at $555^{\circ} \mathrm{C}$ similar to MCNR depicting titanomagnetite. KC-2 showed a peak at 410 and minimum $K \mathrm{lf}$ at $510^{\circ} \mathrm{C}$, with peak diamagnetic $K$ lf at $565^{\circ} \mathrm{C}$. The reverse gain started at $475^{\circ} \mathrm{C}$ with a reverse peak of $365^{\circ} \mathrm{C}$. It showed $100 \%$ drop by recording zero susceptibility at $50^{\circ} \mathrm{C}$. KB-2 showed a peak at $220^{\circ} \mathrm{C}$ and minimum $\mathrm{Klf}$ at $545^{\circ} \mathrm{C}$ with a reverse gain at $565^{\circ} \mathrm{C}$. $\mathrm{K}+\mathrm{J}-2$ showed a peak at $275^{\circ} \mathrm{C}$ and minimum $K$ lf ideally falling at $575^{\circ} \mathrm{C}$, depicting Curie temperature of magnetite. ISRWAD-3 showed a peak at $170^{\circ} \mathrm{C}$ with minimum $K$ lf occurring at $505^{\circ} \mathrm{C}$ and maximum diamagnetism at $570^{\circ} \mathrm{C}$. DHGN-2 showed a peak at $155^{\circ} \mathrm{C}$ and minimum at $475^{\circ} \mathrm{C}$ with diamagnetic peak occurring at $540^{\circ} \mathrm{C}$. B-1 showed a peak at $225^{\circ} \mathrm{C}$ and minimum value at $520^{\circ} \mathrm{C}$. The modern pottery sample (no. 10) showed a peak at $315^{\circ} \mathrm{C}$ and minimum at $475^{\circ} \mathrm{C}$. The other modern sample showed a peak at $95^{\circ} \mathrm{C}$ and minimum at $580^{\circ} \mathrm{C}$.

Majority of the $K-T$ curves show a drop (to zero) after $580^{\circ} \mathrm{C}$, indicating magnetite and titanomagnetite as the primary minerals (Figure 3). However, magnetic 
RESEARCH ARTICLES

Table 2. An account of susceptibility - temperature data of ancient and modern pottery further used for cluster analysis

\begin{tabular}{|c|c|c|c|c|c|c|c|c|c|}
\hline Sample & $\begin{array}{c}\chi_{\text {If }} \\
\text { at room } \mathrm{T}\end{array}$ & $\begin{array}{c}\mathrm{T} \text { of } \\
\text { peak } K \mathrm{lf}\end{array}$ & $\begin{array}{c}\mathrm{T} \text { for } \\
K \text { lf drop }\end{array}$ & $\begin{array}{c}\text { Klf } \\
\text { minima }\end{array}$ & Dia. $\chi_{\text {lf }}$ & $\begin{array}{l}\text { Dia. peak } \\
\text { temp. }\end{array}$ & $\begin{array}{c}\text { Reverse } \\
\text { gain }\end{array}$ & $\begin{array}{l}\text { Reverse } \\
\text { peak } K l f\end{array}$ & $\begin{array}{l}\text { Percentage } \\
\text { drop in } K \text { lf }\end{array}$ \\
\hline SVR-3 & 18.08 & 295 & 485 & 555 & -12.88 & 600 & 395 & 280 & 98.63 \\
\hline SVR-2 & 6.32 & 375 & 500 & 605 & -4.47 & 650 & 495 & 300 & 100 \\
\hline SGN-2 & 71.75 & 445 & 530 & 545 & -40.88 & 585 & 520 & 405 & 99.41 \\
\hline MCNR-2 & 47.12 & 105 & 250 & 245 & -23.17 & 555 & 240 & 275 & 100 \\
\hline KGN-1 & 28.28 & 220 & 280 & 495 & -13.97 & 555 & 375 & 275 & 100 \\
\hline $\mathrm{KC}-2$ & 49.30 & 410 & 485 & 510 & -27.30 & 565 & 475 & 365 & 100 \\
\hline $\mathrm{KB}-2$ & 32.12 & 220 & 425 & 545 & -13.35 & 565 & 420 & 290 & 101.29 \\
\hline $\mathrm{K}+\mathrm{J}-2$ & 37.07 & 275 & 485 & 575 & -13.39 & 585 & 465 & 260 & 89.07 \\
\hline ISRWAD-3 & 24.45 & 170 & 335 & 505 & -15.60 & 570 & 375 & 215 & 97.14 \\
\hline DHGN-2 & 37.058 & 155 & 280 & 475 & -18.38 & 540 & 285 & 205 & 96.06 \\
\hline B-1 & 20.17 & 225 & 475 & 520 & -9.44 & 550 & 420 & 195 & 97.87 \\
\hline Modern 10 & 26.34 & 315 & 350 & 475 & -4.72 & 600 & 215 & 280 & 100 \\
\hline Modern 4 & 9.77 & 95 & 290 & 580 & -5.29 & 520 & 465 & 160 & 100 \\
\hline
\end{tabular}

T, Temperature in degree celsius; Dia, Diamagnetic.

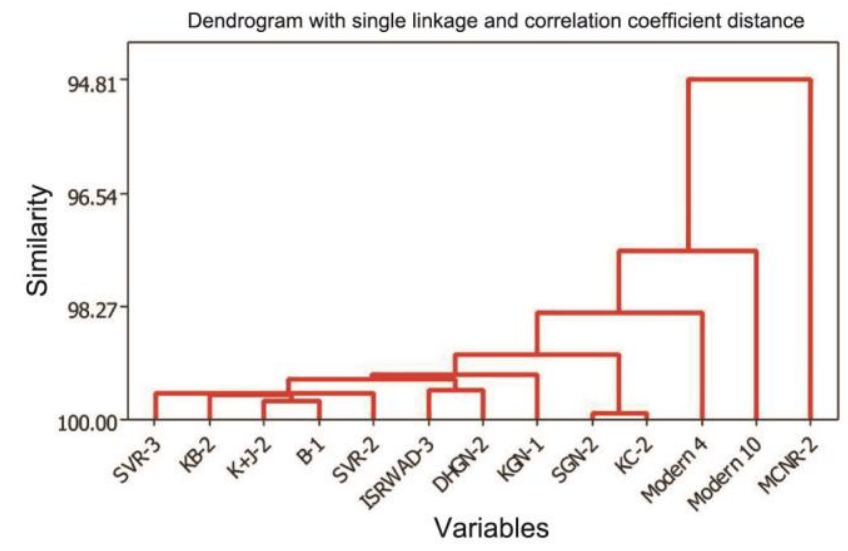

Figure 4. Cluster analysis dendrogram for $k-T$ data given in Table 2 and Supplementary Table 6.

susceptibility becomes negative (diamagnetic) beyond this temperature, indicating the predominance of quartz in all these samples dominating diamagnetic susceptibility after reaching the ferromagnetic $T_{\mathrm{c}}$. We further applied cluster analysis to determine the nearness of pottery source based on thermomagnetic data.

The susceptibility-temperature data (Table 2) subjected to cluster analysis show similarity/nearness amongst different potteries within the Deccan province (Figure 4). The potsherds of SVR-3, KB-2, K+J-2, B-1 and SVR-2 formed one group, while ISRWAD-3 and DHGN formed another group. SGN-2 and KC-2 also formed a separate group. All these potteries further showed similarity, while the modern potteries formed a distinctly separate group. The pottery from MCNR-2 was not grouped with any other studied collection. Overall the thermomagnetic study indicated a large and irreversible change in Klf as a function of temperature. The low ferrimagnetic concentration was readily converted to weak antiferromagnetic Klf dominated by diamagnetic susceptibility. The Klf after heating was always lower indicating that there was no significant addition from the oxidation of other ferrimagnesian minerals. If heating produced ferric oxides, the susceptibilities were weak to be detected and the Klf was dominated by the ferrimagnetism. Further the heating appears to have partially converted the ferrimagnetic minerals.

\section{Mineral magnetic characteristics of Deccan-sourced pottery}

The high magnetic susceptibilities in the modern sediments and soils of Deccan basalts are due to the presence of detrital (/lithic/clastic) grains. The lower susceptibilities are therefore proportional to successive removal of the coarse detrital grains against the enrichment of fine clay and silt material. $\chi_{\mathrm{lf}}$ in the Deccan-sourced pottery is therefore directly indicative of the degree of processing of raw material for potteries, bricks and other ceramic artifacts. The lower susceptibilities in modern potteries compared to ancient potteries too therefore attest an efficient removal of sand/silt fraction. This is attested by the low volume susceptibility for Gangetic soils (about $1 / 20$ th of the Deccan soils) due to the alluvial nature of the Ganga plains having low ferrimagnetic concentration relative to the Deccan soils. The potteries sourced from any fringe areas of the Deccan Province have nonbasaltic source anticipating such lower values. The distinct high/low susceptibility criterion therefore can be used as a rapid measure to distinguish between the Deccan and non-Deccan source of the artifacts. More detailed characterization of other (non-Deccan) provinces would therefore provide a database to identify the source for pottery, with great implications to study the trade pathways.

The $\chi_{\mathrm{fd}} \%$ for modern soils of Deccan and UP show low values (less than $2 \%$ ), whereas the representative high $\chi_{\text {fd }}$ in their pottery suggests that the SP fraction is generated during firing. The IRM contribution to 

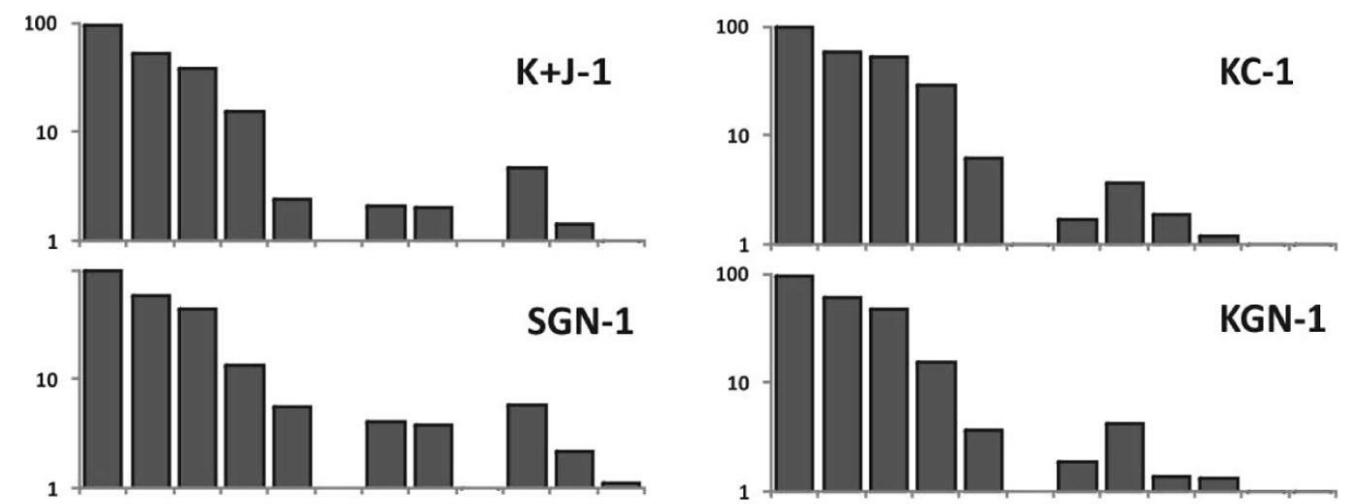

100

KGN-1
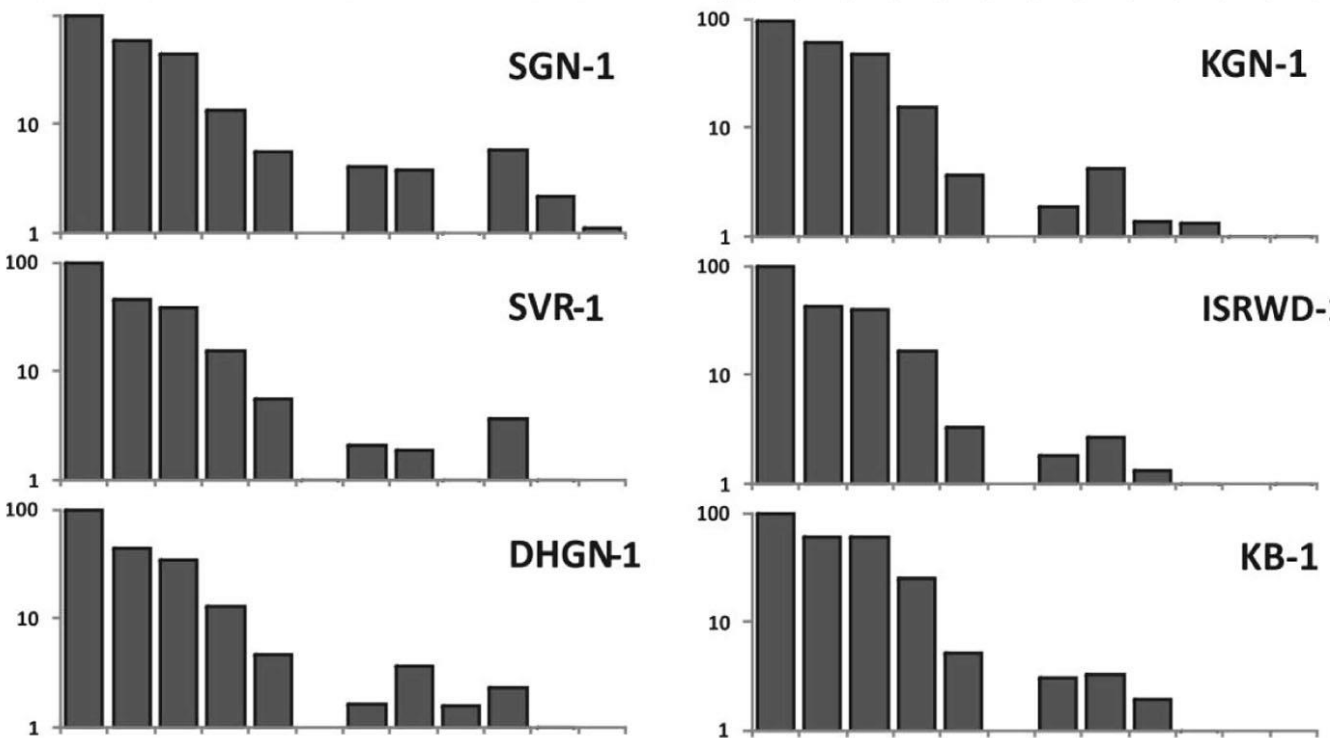

100

SRWD-1

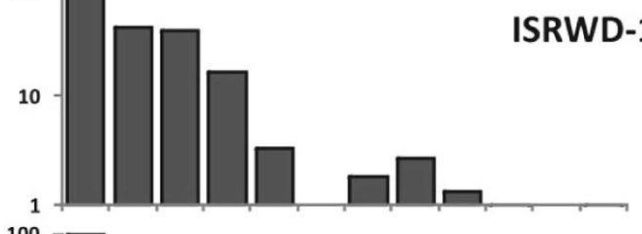

100

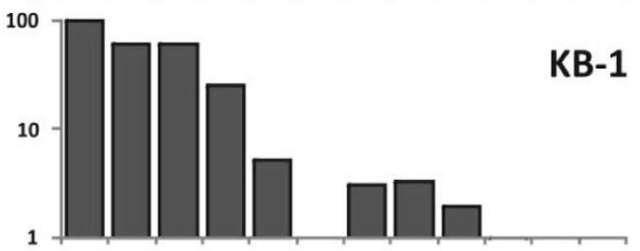

100

MCNR-1

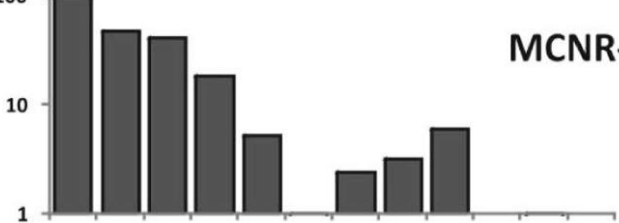

100

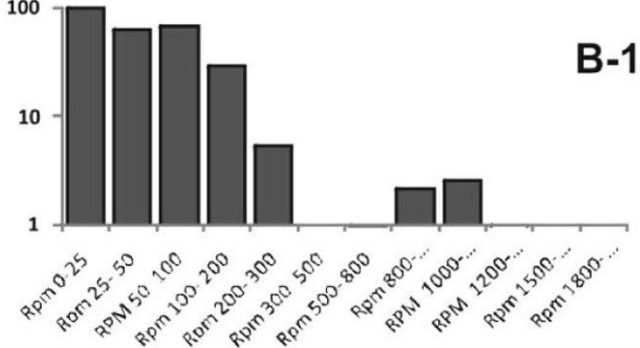

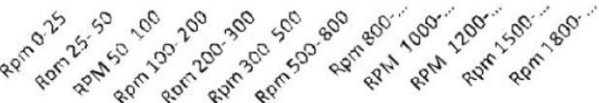

Figure 5. Rates of isothermal remanence magnetization acquisition shown by bar diagram on logarithmic scale for the ancient pottery. Details discussed in text.

antiferromagnetic concentration is high for modern pottery compared to ancient pottery. This is due to prolonged heating of the modern pottery in air and under more oxygenated environments. The higher SD content in ancient pottery may be due to their preservation in less oxygenated environments. This demands more data with mineral magnetic experiments from well-established typologies. All other mineral magnetic parameters infer a higher detrital content for the ancient pottery compared to modern pottery.

Based on detailed examination of the rates of IRM acquisition (RPM values), we found two major groups for the studied samples, viz. up to $300 \mathrm{mT}$, and from 500 to $1800 \mathrm{mT}$ respectively (Figure 5). The first group is due to predominant ferrimagnetic composition and the second group is due to a mixture of paramagnetic and antiferromagnetic oxides. Therefore, in order to find a relative change in concentration of antiferromagnetic to ferrimag- netic oxides, we propose a simple ratio of IRM $_{1.8 \mathrm{mT}} /$ $\mathrm{IRM}_{0.3-0.025 \mathrm{mT}}$ to indicate oxidative transformation. Another ratio on similar grounds is suggested here, i.e. HIRM/Soft IRM to distinguish between relative concentration of ferrimagnetic and antiferromagnetic materials to depict the levels of oxidative firing. Overall, the results indicate that the routine mineral magnetic studies can be used as a distinctive tool to characterize the pottery and potsherds. However, further mineral magnetic experiments combined with petrographic and spectroscopic studies are needed to develop a robust quantitaive database on potsherds for precise documentation the technological and cultural aspects.

\section{Conclusion}

The mineral magnetic studies on potsherds sourced from the Deccan soils and sediments have depicted 
discriminative values for the Deccan-sourced potsherds. The present study further provides a rapid approach to estimate the relative degree of pre-processing of pottery material from the Deccan Province. Based on the mineral magnetic experiments, we suggest the parameters IRM $_{1.8 \mathrm{mT}} / \mathrm{IRM}_{0.3-0.025 \mathrm{mT}}$ and HIRM/Soft IRM $_{\text {Ho indicate }}$ the relative degree of oxidative heating amongst the potsherds. The mineral magnetic approach therefore facilitates: (i) rapid discrimination of the source, (ii) levels of pre-processing of the artifacts and (iii) the relative degree of oxidative heating. The study shows great scope for similar attempts on potsherds from other archeological provinces to reconstruct the pottery-making techniques and trade pathways.

1. Shepard, A. O., Ceramics for the Archaeologist, Carnegie Institute of Washington, 1956, p. 414.

2. Rye, O. S., Pottery Technology: Principles and Reconstruction (Vol. 4), Taraxacum, Washington, DC, USA, 1981.

3. Rice, P. M., Pottery Analysis: A Sourcebook, University of Chicago Press, Chicago, USA, 2015, p. 447.

4. Yoon, Y., Kim, T., Yang, M., Lee, K. and Lee, G., Quantitative analysis of pottery glaze by laser induced breakdown spectroscopy. Microchem. J., 2001, 68(2-3), 251-256.

5. Martineau, R., Walter-Simonnet, A. V., Grobéty, B. and Buatier, M., Clay resources and technical choices for Neolithic pottery (Chalain, Jura, France): chemical, mineralogical and grain-size analyses. Archaeometry, 2007, 49(1), 23-52.

6. Thompson, R. and Oldfield, F., Environmental Magnetism, Allen and Unwin Press, London, UK, 1986, p. 227.

7. Heller, F. and Evans, M. E., Loess magnetism. Rev. Geophys., 1995, 33(2), 211-240.

8. Liu, Q., Roberts, A. P., Larrasoana, J. C., Banerjee, S. K., Guyodo, Y., Tauxe, L. and Oldfield, F., Environmental magnetism: principles and applications. Rev. Geophys., 2012, 50(4), 1-50.

9. Venkatachalapathy, R., Sridharan, T., Dhanapandian, S. and Manoharan, C., Determination of firing temperature of ancient potteries by means of infrared and Mossbauer studies. Spectrosc. Lett., 2002, 35(6), 769-779.

10. Venkatachalapathy, R., Bakas, T., Basavaiah, N. and Deenadayalan, K., Mossbauer and mineral magnetic studies on archaeological potteries from Adhichanalur, Tamil Nadu, India. Hyperfine Interact., 2008, 186, 89-98.

11. Manoharan, C., Venkatachalapathy, R., Dhanapandian, S. and Deenadayalanm, K., FTIR and Mossbauer spectroscopy applied to study of archaeological artifacts from Maligaimedu, Tamil Nadu, India. Indian J. Pure Appl. Phys., 2007, 45, 860-865.

12. Manoharan, C., Veeramuthu, K., Venkatachalapathy, R., Radhakrishna, T. and Ilango, R., Spectroscopic and ancient geomagnetic field intensity studies on archaeological pottery samples, India. Lith. J. Phys., 2008, 48(2), 195-202.

13. Dhanapandian, S., Manoharan, C. and Sutharsan, P., Applications of FTIR and $57 \mathrm{Fe}$ Mossbauer techniques in studies of recently excavated Indian archaeological pottery. Acta Phys. Pol. A, 2012, 121, 592-598

14. Warrier, A. K. and Shankar, R., Geochemical evidence for the use of magnetic susceptibility as a paleorainfall proxy in the tropics. Chem. Geol., 2009, 265(3), 553-555.

15. Maher, B. A., Characterisation of soils by mineral magnetic measurements. Physics Earth Planet. Inter., 1986, 42(1-2), 76-92.

16. Singer, M. J. and Fine, P., Pedogenic factors affecting magnetic susceptibility of northern California soils. Soil Sci. Soc. Am. J., 1989, 53(4), 1119-1127.

17. Jordanova, D., Goddu, S. R., Kotsev, T. and Jordanova, N., Industrial contamination of alluvial soils near $\mathrm{Fe}-\mathrm{Pb}$ mining site revealed by magnetic and geochemical studies. Geoderma, 2013, 192, 237-248.

18. Torrent, J., Liu, Q. S. and Barrón, V., Magnetic minerals in Calcic Luvisols (chromic) developed in a warm Mediterranean region of Spain: origin and paleoenvironmental significance. Geoderma, 2010, 154(3), 465-472.

19. Balsam, W. L., Ellwood, B. B., Ji, J., Williams, E. R., Long, X. and El Hassani, A., Magnetic susceptibility as a proxy for rainfall: worldwide data from tropical and temperate climate. Quater. Sci. Rev. [online], 2011, 30(19-20), 2732-2744.

20. Sabale, P. D. and Kshirsagar, S. D., A preliminary report on geoarchaeological explorations in upper reaches of Sina river basin: a case study of Ahmednagar, Bid, Osmanabad and Solapur districts of MS. Bull. Deccan Coll., 2014, 74, 9-20.

21. Shivaji, K., Mishra, S. and Sabale, P. D., Some Acheulian localities in the Sina basin. Bull. Deccan Coll., 2014, 74, 21-26.

22. Dearing, J., Magnetic susceptibility. In Environmental Magnetism: A Practical Guide, 1999, vol. 6, pp. 35-62.

23. Mullins, N. C., Hargens, L. L., Hecht, P. K. and Kick, E. L., The group structure of cocitation clusters: a comparative study. Am. Sociol. Rev., 1977, 42, 552-562.

24. Verosub, K. L. and Roberts, A. P., Environmental magnetism: past, present, and future. J. Geophys. Res.: Solid Earth, 1995, 100(62), 2175-2192.

25. Maher, B. A., Magnetic properties of modern soils and Quaternary loessic plaeosols: paleoclimate implications. Palaeogeogr., Palaeoclimatol., Palaeoecol., 1998, 137(1-2), 25-54.

26. Kale, V. S., Dole, G., Upasani, D. and Patil Pillai, S., Deccan Plateau uplift: insights from parts of Western Uplands, Maharashtra, India. Geological Society, London, Spl. Publ. 445, 2016, pp. 11-46; doi:org/10.1144/SP445.2.

ACKNOWLEDGEMENTS. We thank the anonymous reviewers for critical review of the manuscript. We also thank Dr Vasant Shinde (Deccan College PGRI, Pune) for guidance, encouragement and suggestions. The Head, Department of Geology, Savitribai Phule Pune University, Pune is acknowledged for providing the necessary facilities and the Department of Science and Technology, New Delhi for support under DST-FIST programme (grant SR/FST/ESII-101/2010).

Received 27 December 2017; revised accepted 1 April 2019

doi: $10.18520 / \mathrm{cs} / \mathrm{v} 117 / \mathrm{i} 2 / 251-259$ 